\title{
An experimental method of measuring the quasi-static and dynamic confined behaviour of PMMA
}

\author{
P. Forquin ${ }^{1, a}$, M. Nasraoui ${ }^{1,2}$, L. Siad ${ }^{2}$, and A. Rusinek ${ }^{3}$ \\ ${ }^{1}$ Laboratory of Physics and Mechanics of Materials, Université Paul Verlaine - Metz, Ile du Saulcy, \\ 57045 Metz cedex 1, France \\ ${ }^{2}$ URCA/GRESPI/LMN, Université de Reims, BP 1039, 51687 Reims cedex 2, France \\ ${ }^{3}$ Laboratory of mechanics, Biomechanics, Polymers and Structures (LABPS), National Engineering \\ School of Metz (ENIM), Ile du Saulcy, 57000 Metz cedex 1, France
}

\begin{abstract}
A testing device is presented for the experimental study of the confined behaviour of PMMA in compression under quasi-static loading or at high strain-rates. The constitutive relation of the material ring (allowing to confine the PMMA) being known, transverse gauges glued on its lateral surface allow for the measurement of the lateral confining pressure. The hydrostatic pressure and the Mises stress may be computed. Quasi-static and dynamic tests performed in a strain-rate range of $1 \mathrm{e}-3 / \mathrm{s}$ $1 \mathrm{e} 3 / \mathrm{s}$ are processed with the method and compared to results of unconfined compression tests. It is found that the compressive behaviour of PMMA is weakly influenced by the level of pressure and much more sensitive to strain-rate: an elastic brittle behaviour is observed at high strain-rates in unconfined or confined conditions whereas elastoplastic behaviour is noted under quasi-static loading.
\end{abstract}

\section{Introduction}

PMMA (Poly methyl methacrylate) is a thermoplastic polymer widely used as protective structure in aeronautics, nuclear industry, and machinery equipment, against shocks or ballistic impacts. To improve the design of such structures based on numerical simulation the mechanical behaviour of PMMA under high confining pressure and high strain-rates must be investigated [1]. In this context, the behaviour of PMMA has been widely studied in the last decades through unconfined compression tests as function of temperature and strain-rate [2-4]. In quasi-static conditions a cylindrical specimen is placed between parallel platens and loaded through a hydraulic press. The authors have observed a continuous increase of the compressive yield stress with strain-rate and negative temperature sensitivity in the explored range from $-120^{\circ} \mathrm{C}$ to the glass temperature transition $\left(\mathrm{T}_{\mathrm{g}}=105^{\circ} \mathrm{C}\right)$ [5]. Split Hopkinson Pressure Bar device is generally used to reach strainrates of few thousands per second [3, 6-7]. The yield stress is tripled in the range (1e-3/s - 1e $3 / \mathrm{s})$ and a strong softening is observed in dynamic conditions [2-3]. Brittleness of PMMA at high strain-rates has been also observed in puncture tests by impact [4]. During an impact, the target is subjected to compressive stresses and high pressures in the vicinity of the impact point and tensile stresses further

\footnotetext{
a e-mail : pascal.forquin@univ-metz.fr
} 
down that may induce cracking and breaking of the target. Therefore, the response of PMMA under high confining pressure is a key-parameter to be considered for numerically simulating the behaviour of PMMA structures subjected to impact loading [1]. In this work, quasi-static and dynamic quasioedometric compression tests have been developed and performed. The processing method and some experimental results are described below.

\section{Description of the confined compression tests}

\subsection{Principle}

At first sight, Quasi-Oedometric Compression (QOC) tests have been developed to test out geomaterials as concretes, rocks or soils under high confining pressures. The principle is the following: a cylindrical specimen tightly enclosed in a confinement vessel is axially compressed. As it tends to expand, both radial and axial stresses increase in the specimen. The test provides a reading of the strength of the material at different levels of pressure. Several experimental devices for quasioedometric compression were proposed by Bažant et al. [8], Burlion [9] and Gatuingt [10]. Burlion et al. [11], for instance, developed an instrumented elastic steel vessel. Forquin et al. [12-14] proposed a new analysis of experimental data taking account of the shortening of specimen and of a possible plastic deformation of the confining cell. More recently, dynamic QOC tests have been performed with a split-Hopkinson pressure bar device in the range of strain-rates from 80 to 200/s applying the previous methodology [15-16]. The accuracy of the method and the influence of friction were specially discussed. The steel ring allows for exploring the behaviour of concrete under levels of lateral pressure up to $800 \mathrm{MPa}$. In particular, these tests revealed a huge influence of free water on the dynamic strength of concrete under high confining pressures [16].

In the present study, cylindrical specimen of PMMA $10 \mathrm{~mm}$ in diameter and $14 \mathrm{~mm}$ in length enclosed in a confinement vessel is subjected to axial compression through a universal testing machine and compression plugs made of high strength steel (Fig. 1b). The brass confinement vessel is a crown of $10 \mathrm{~mm}$ as inner diameter, $22 \mathrm{~mm}$ as outer diameter and $16 \mathrm{~mm}$ in length. The axial stress in the specimen is calculated from the load cell. LVDTs are attached to compression platens to measure the axial strain. The radial strain and stress in the specimen are deduced from the hoop micro-strain measured through $\mathrm{G}_{1}$ strain gauge attached on the outer surface of the vessel (Fig. 1a). Hoop strain gauges $G_{2}$ and $G_{3}$ are located at a distance from the middle equal to $3 / 4$ of the half-length of the ring. As axial strain gauge $\mathrm{G}_{2}, \mathrm{G}_{3}$ and $\mathrm{G}_{4}$ are used to evaluate the barrelling of the ring, by comparison with the central gauges $\mathrm{G}_{1}$. They also indirectly provide an evaluation of the difference in axial displacement between the specimen and the ring.
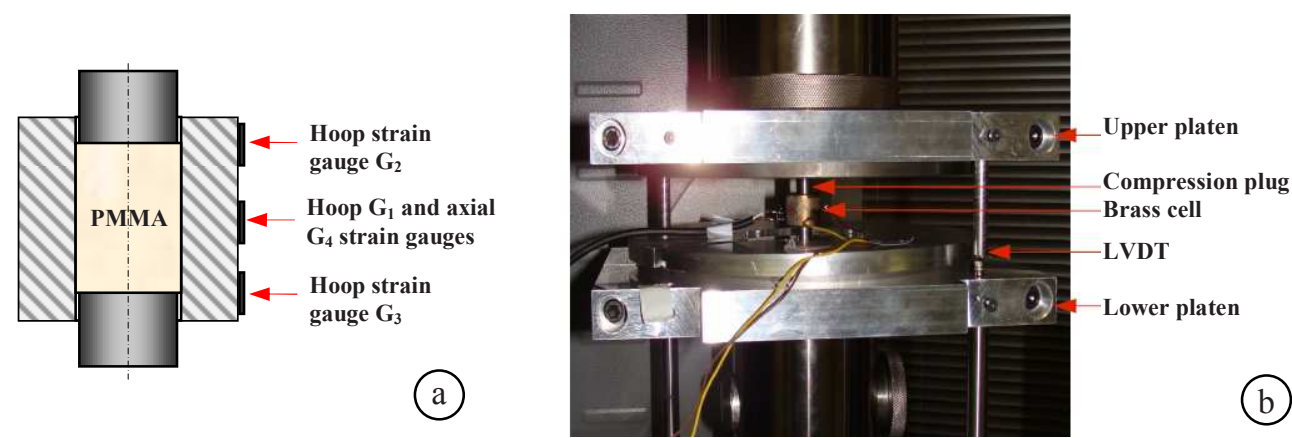

Fig.1. Device and instrumentation used for quasi-static quasi-oedometric compression tests. 


\subsection{Processing method}

With the aim to evaluate from $\mathrm{G}_{1}$ strain measurement the average contact pressure between the vessel and the specimen, a series of numerical simulations have been performed that takes into account the elasto-plastic behaviour of the vessel material $[12,15]$. First, the constitutive law of brass has been identified from a quasi-static tensile test (Fig. 2).

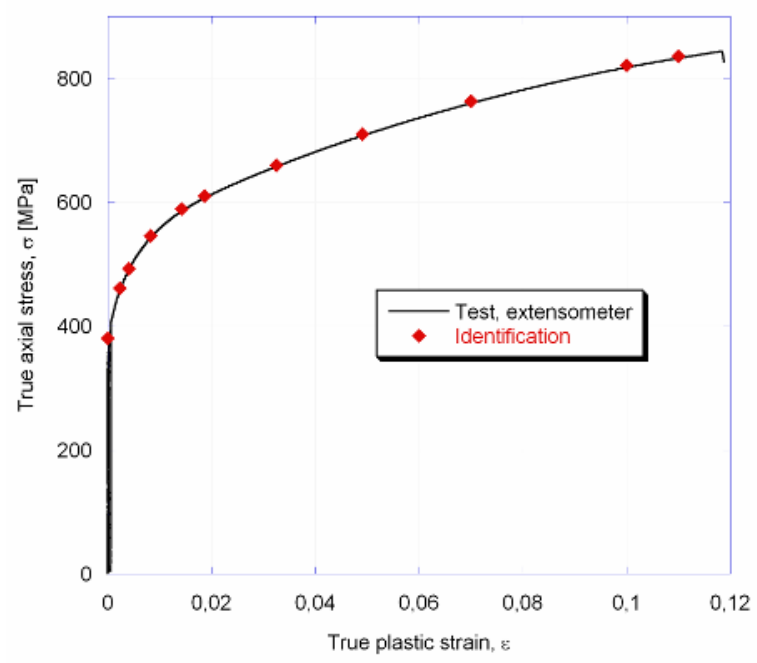

Fig. 2. Identification of the constitutive law of brass from a tensile test under quasi-static loading

Next, three computations have been performed using 4-nodes axisymmetric elements and Abaqus-standard FE code. For the first simulation, a radial compression is applied on the inner cylindrical surface of the vessel through a length of $14 \mathrm{~mm}$ (the initial length of the specimen). The computation provides a relation between the external hoop strain and the internal radial stress (Fig. $3)$. For the second and third simulations, $12 \mathrm{~mm}$ and $10 \mathrm{~mm}$ are considered.

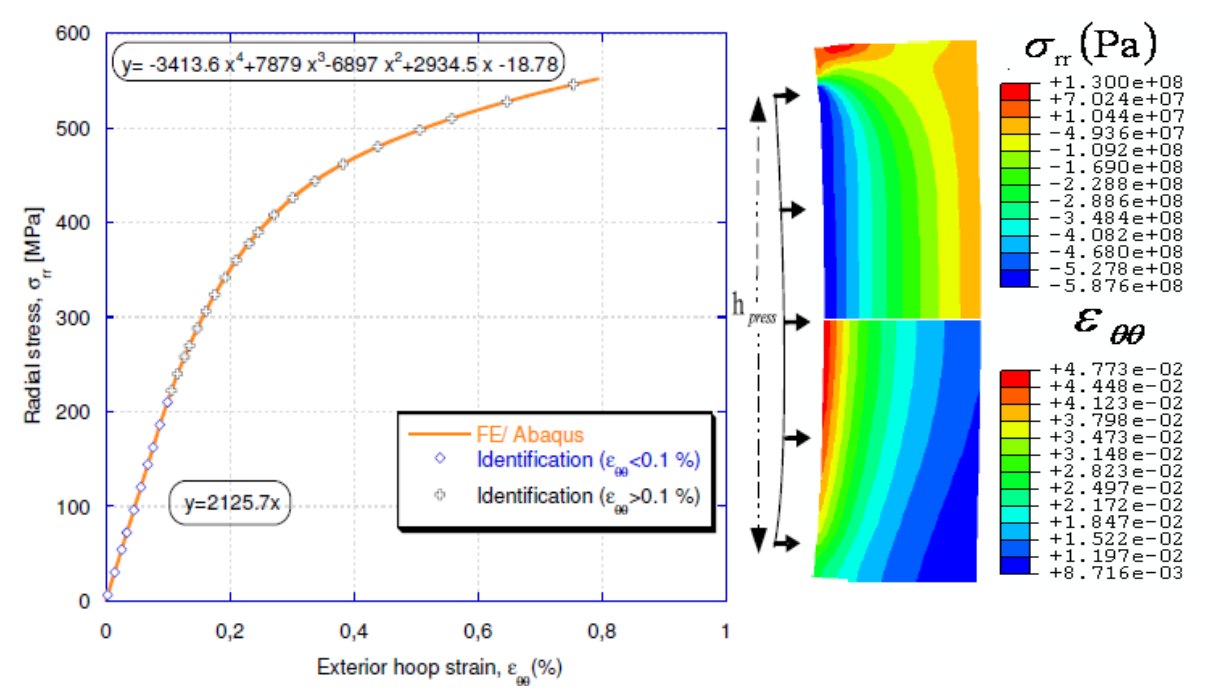

Fig. 3. Relation between the external hoop strain and the internal radial stress applied on $14 \mathrm{~mm}$. 
Using simple interpolation of the results provided by the three numerical simulations, the change of specimen length is accounted for in the processing of data (Eqn. 1).

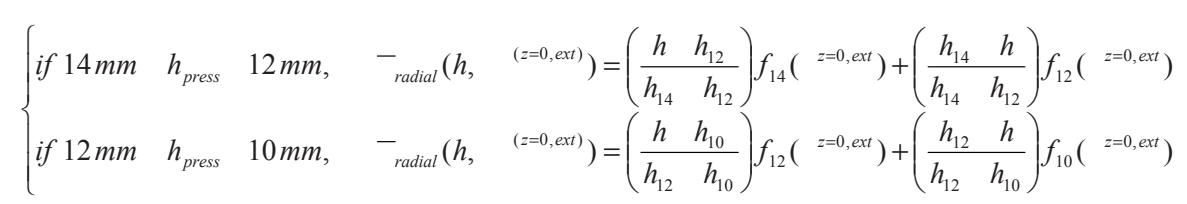

where the functions $\left(f_{14}, f_{12}\right.$ and $\left.f_{10}\right)$ are identified from numerical simulations. In a similar way, the average radial strain $\left({ }^{-}\right.$radial $)$in the specimen is deduced from data of gauges $\mathrm{G}_{1}, \mathrm{G}_{2}$ and $\mathrm{G}_{3}$ [12]. Next, the axial load being known, the average axial stress may be also computed:

$$
-_{\text {axial }}=\frac{F_{\text {axial }}}{r_{0}^{2}\left(1+-_{\text {radial }}\right)^{2}} .
$$

Knowing the mean axial stress and radial stress, the von Mises stress and the hydrostatic pressure are then given by:

$$
-_{\text {von Mises }}=\left|-_{\text {axial }}-_{\text {radial }}\right|, \quad P_{\text {hydrostatic }}=\frac{1}{3}\left(-_{\text {axial }}+2-_{\text {radial }}\right)
$$

Now, the von Mises stress may be plotted as function of axial strain and hydrostatic pressure. This methodology is applied herein to quasi-static and dynamic quasi-oedometric compression tests.

\section{Results of quasi-oedometric compression tests}

\subsection{Quasi-static tests}

A series of quasi-static quasi-oedometric compression tests have been carried out. The variations with respect to axial strain of radial stress, axial stress, hydrostatic pressure and von Mises stress are plotted in Fig. 4 for one test performed at $0.001 / \mathrm{s}$. It is observed from this figure that the hydrostatic pressure increases to roughly $550 \mathrm{MPa}$ during experiments. Under such confining pressures, PMMA exhibits an elastic perfectly plastic behaviour with a maximum strength about $160 \mathrm{MPa}$ (Fig. 4), to be compared to unconfined strength measured in uniaxial compression test (about $130 \mathrm{MPa}$, Fig. 4). Moreover, the level of friction at specimen-vessel interface has been evaluated by comparing the change of hoop strains ratio $\left(\mathrm{G}_{2}+\mathrm{G}_{3}\right) / 2 \mathrm{G}_{1}$ with numerical data (Fig. 5). Indeed, the higher the friction between the specimen and the vessel, the more marked the barrelling deformation of the vessel, the lower this ratio. Thus, numerical simulation of a vessel subjected to an internal pressure through $12 \mathrm{~mm}$ and tangential stresses corresponding to $0,10 \%$ or $20 \%$ of the internal pressure have been performed. Comparison of experimental data and numerical data allows estimating that friction coefficient is lower than 0.1 (Fig. 5). 


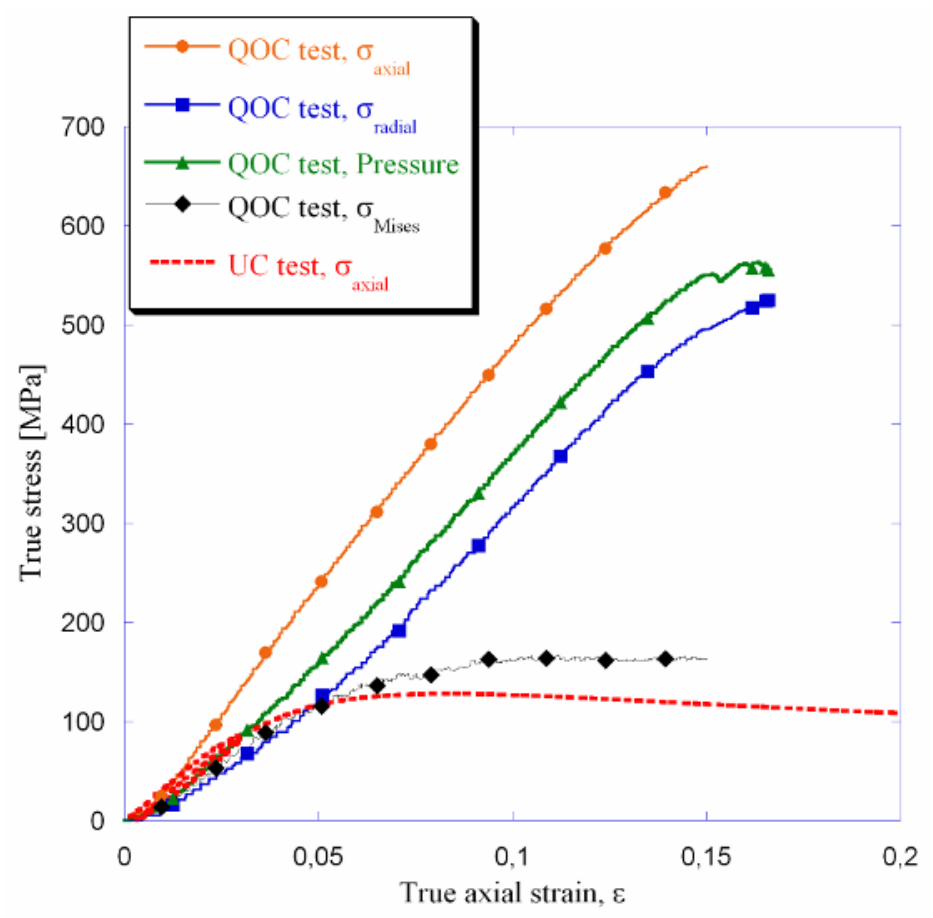

Fig. 4. Quasi-static quasi-oedometric compression test (brass vessel, strain rate: 0.001/s) compared to a uniaxial compression test.

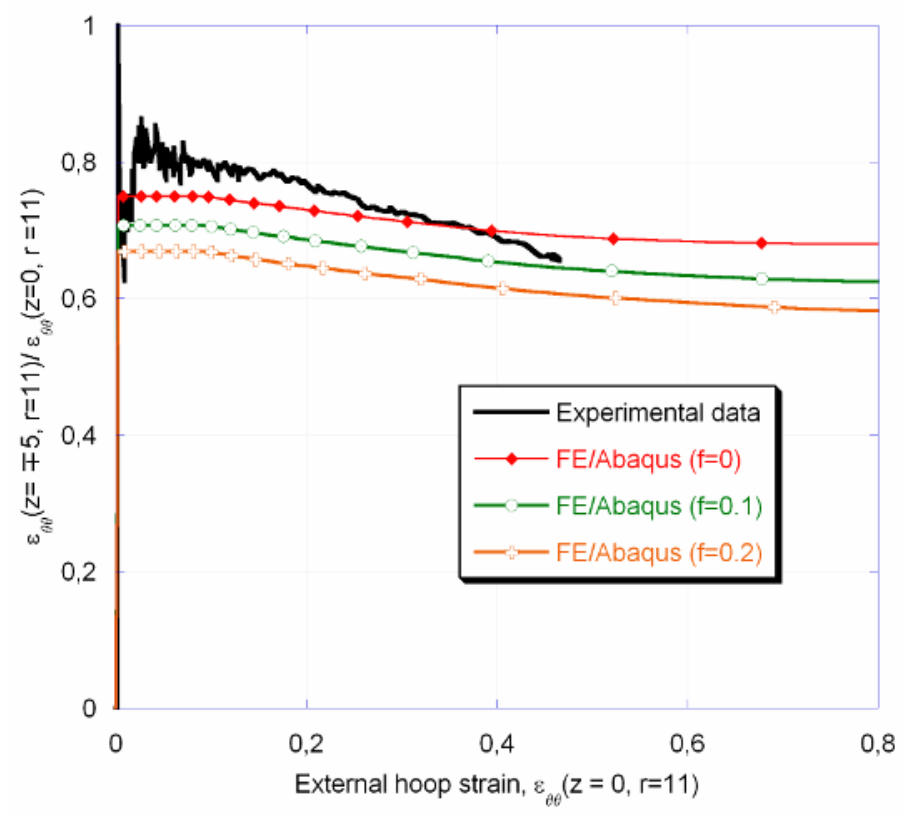

Fig. 5. Ratio of external hoop strains $\left(G_{2}+G_{3}\right) / 2 G_{1}$ as function of $G_{1}$. Comparison of experimental data to numerical simulation of a vessel subjected to an internal pressure through $12 \mathrm{~mm}$ and tangential stresses corresponding to $0,10 \%$ or $20 \%$ of the internal pressure. 


\subsection{Dynamic tests}

In parallel, a Split-Hopkinson-Pressure-Bar device (SHPB) has been used to identify the unconfined and confined strength of PMMA at high strain-rates (2000-4000/s). This experimental set-up, widely used today, was pioneered by Kolsky [17]. In this work, a device composed of two high strength steel bars (input and output bars, $1.5 \mathrm{~m}$ in length, $20 \mathrm{~mm}$ in diameter) and projectiles of length 400 or $600 \mathrm{~mm}$ has been used. Gauges glued on the input and output bars allows for the knowledge of forces and particle velocities at both faces of the specimen. Forces provide the change of axial stress in the specimen whereas particle velocities are integrated to deduce the change of axial strain as function of time. Next, the processing method described previously is applied (Eqns. $3,4)$. Moreover, brass is assumed to be insensitive to strain-rate and relation (1) is used again.

The evolution of stresses is shown for a QOC test performed with brass vessel. The average strain-rate is about 1430/s. When the maximum von Mises stress is reached (about $330 \mathrm{MPa}$ ), the hydrostatic pressure is equal to $400 \mathrm{MPa}$. One may also observe that the lateral pressure applied by the specimen on the ring (Eqn. 1) is not constant during the test but is continuously increasing. After time $t=80 \mu \mathrm{s}$ axial stress show a sharp fall whereas the radial stress is accelerating. The resulting fall of Mises stress is supposedly due to a breakage within the specimen. Indeed, inclined planes are clearly visible on the failure pattern after the test. Thus, the residual strength observed afterward $(100-250 \mu \mathrm{s})$ is certainly the consequence of rubbing failure planes maintained in contact because of the confinement.

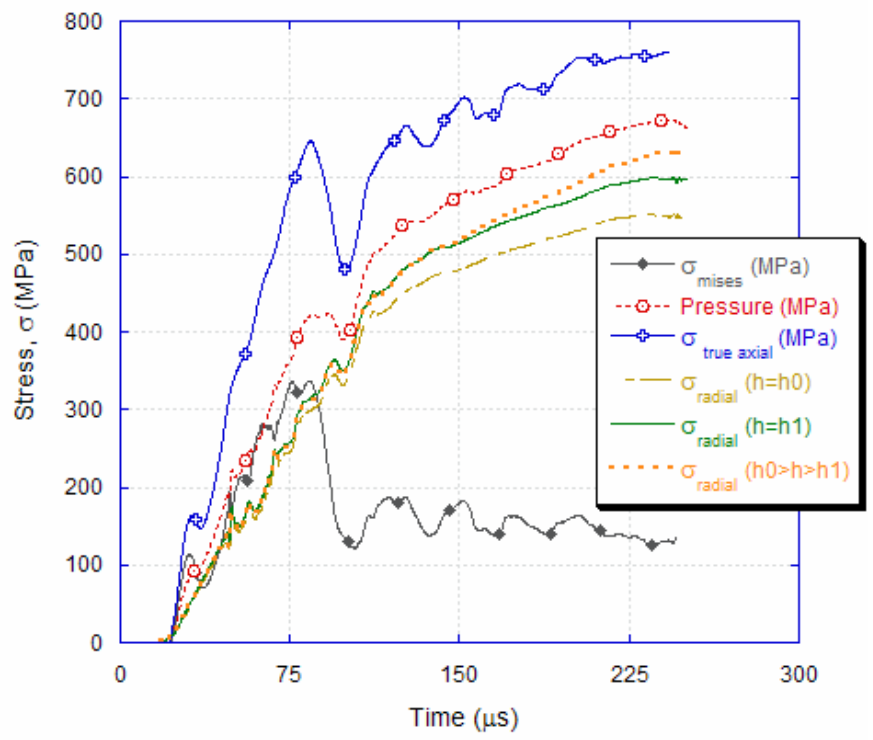

Fig. 6. Change of axial stress, radial stress, von Mises stress and Pressure as function of time in a dynamic QOC test (brass cell).

The change of von Mises stress is plotted as function of axial strain in Fig. 7 for the previous test. An elastic-brittle behaviour is clearly noticed despite the high level of hydrostatic pressure reached during the test. Moreover, the experimental results provided by the quasi-oedometric compression test are compared to those obtained from two dynamic unconfined compression tests performed with the same apparatus (SHPB device). Elastic modulus and yield strain are almost identical, which could be a confirmation of the low influence of the confining pressure on the dynamic strength of PMMA. On the other hand, strain-rate has a strong influence on the dynamic confined strength of PMMA as shown in Fig. 8, where both quasi-static and dynamic quasi-oedometric compression tests 
are compared. According to these results, the brittleness of PMMA under high strain-rate is a keyparameter to be considered for numerically simulating the behaviour of PMMA structures subjected to impact loading.

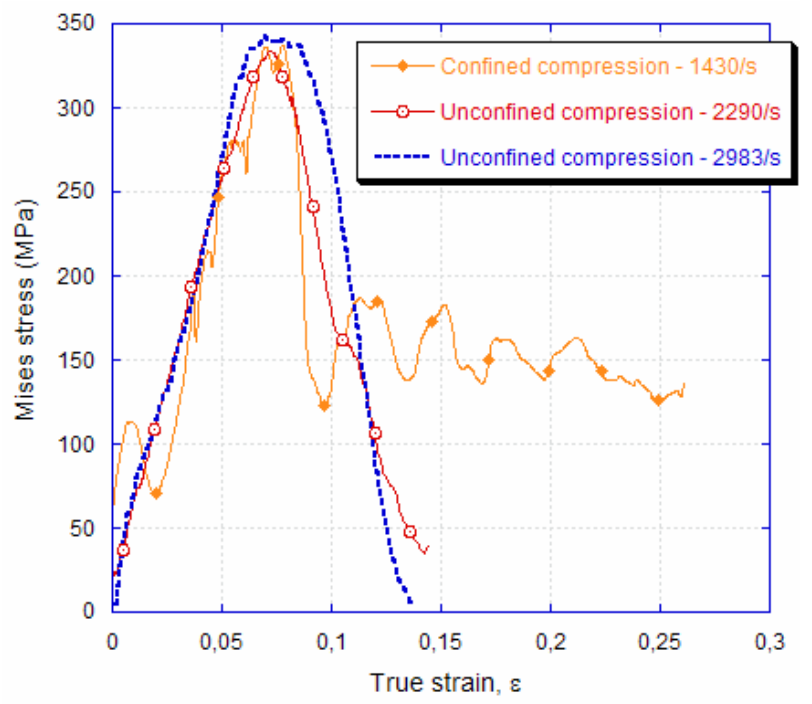

Fig. 7. Comparison between unconfined and quasi-oedometric dynamic compression tests.

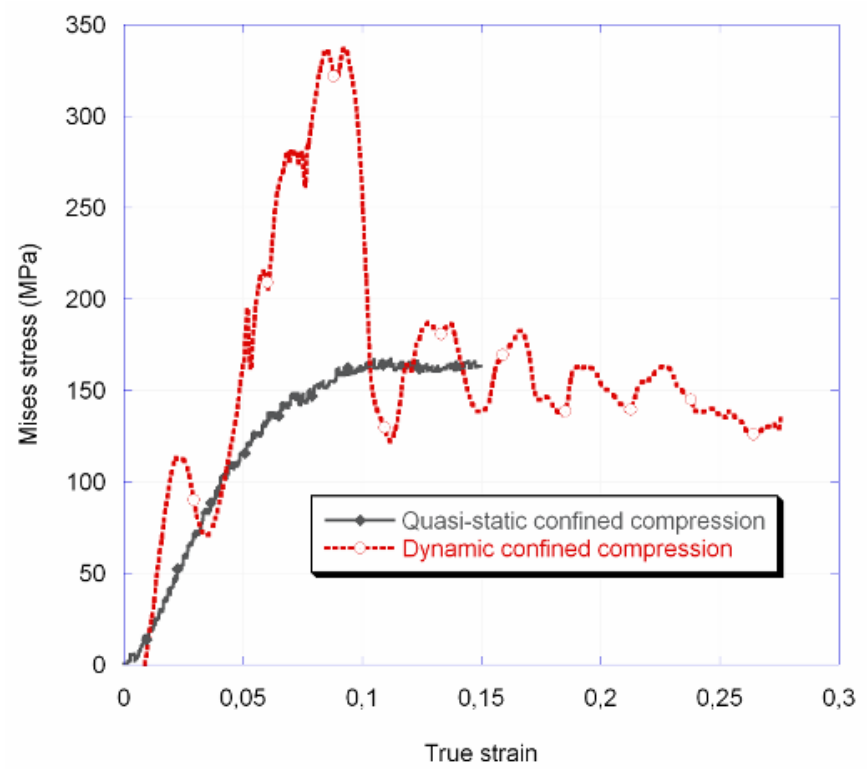

Fig. 8. Comparison between quasi-static and dynamic quasi-oedometric compression tests. 


\section{Conclusion}

Quasi-Oedometric Compression (QOC) tests have been developed to test PMMA in quasi-static or dynamic conditions. Cylindrical specimens of PMMA enclosed in a brass confinement vessel have been subjected to axial compression through a universal testing machine or Split-Hopkinson Pressure Bar device. A processing method has been developed based on numerical simulations of the confining ring loaded by an internal pressure. It allows accounting for the shortening of the specimen and the elasto-plastic behaviour of brass that composed the vessel. Due to the thickness of the ring, hydrostatic pressures as high as $400 \mathrm{MPa}$ have been obtained both in quasi-static and dynamic experiments. According to quasi-static tests, the maximum strength is weakly affected by a confining pressure as the increase of strength is limited to few tens of MPa for the considered level of pressure (few hundreds of $\mathrm{MPa}$ ). On the other hand, an elastic-brittle response is pointed out in dynamic testing with or without confinement and the yield stress is almost unchanged (about $330 \mathrm{MPa}$ ). Finally, this work shows that the level of confining pressure seems to have a limited influence on the quasi-static and dynamic behaviour of PMMA polymer.

\section{References}

1. A. Dorogoy, D. Rittel, A. Brill (2010). Int. J. Imp. Eng, 37 285-294.

2. E.M. Arruda, M.C Boyce, et R. Jayachandran (1995). Mechanics of Materials, 19 193-215.

3. J. Richeton, S. Ahzi, K.S. Vecchio, F.C. Jiang, R.R. Adharapurapu (2006). Int J Solids Struct, $432318-2335$.

4. M. Segreti, A. Rusinek, et J.R. Klepaczko (2004). Polymer Testing, 23 :703-718.

5. J. Richeton, S. Ahzi, L. Daridon, Y. Rémond (2005). Polymer, 46 6035-6043.

6. Z.H. Li, J. Lambros (2001) Int. J. Solids Struct. 38 (20), 3549-3562.

7. D. Rittel, A. Brill (2008), J. Mech. Phys. Solids, 56 (4), 1401-1416.

8. Z.P. Bažant, F.C. Bishop, T.P. Chang, (1986). ACI J. 33, 553-560.

9. N. Burlion. PhD thesis. ENS Cachan, 1997.

10. F. Gatuingt. PhD thesis, ENS Cachan, 1999.

11. N. Burlion, G. Pijaudier-Cabot, N. Dahan (2001). Int. J. Numer. Anal. Meth. Geomech. 25 4671486.

12. P. Forquin, A.A. Arias, R. Zaera (2007). Int. J. Solids Struct. 44, 4291-4317.

13. P. Forquin, A.A. Arias, R. Zaera (2008a). Int. J. Imp. Eng. 35(3) 133-146.

14. P. Forquin, A.A. Arias, R. Zaera (2008b). Exp. Mechanics. doi 10.1007/s11340-008-9172-y.

15. P. Forquin, G. Gary, F. Gatuingt (2008c). Int. J. Imp. Eng. 35(6) 425-446.

16. P. Forquin, K. Safa, G. Gary (2009). Cem. Concr. Res. doi:10.1016/j.cemconres.2009.09.024.

17. H. Kolsky H. (1949). Proceedings of the Physical Society, London, B 62:676-700. 